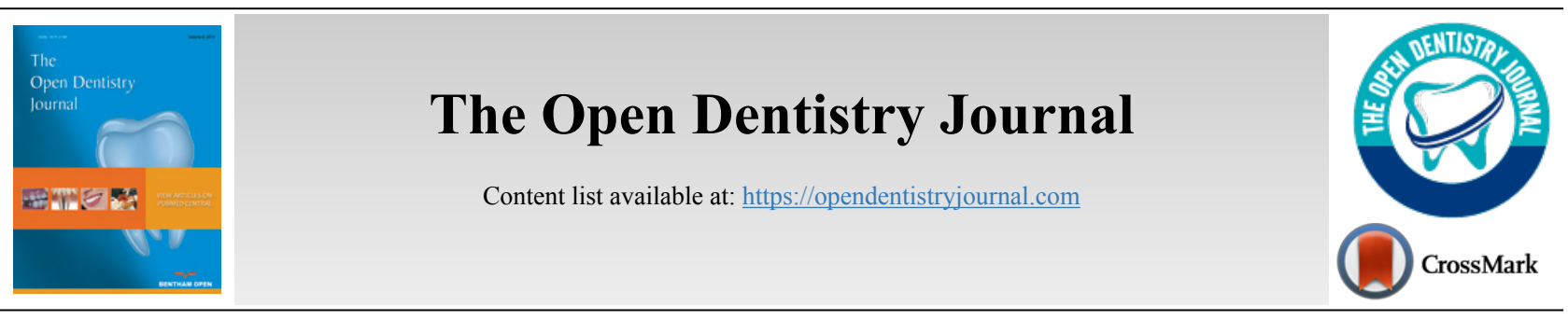

RESEARCH ARTICLE

\title{
S. mutans Serotype c, C. albicans, Oral Hygiene, and Decayed, Missing, and Filled Teeth in Early Childhood Caries
}

\author{
Nurul Rahmah ${ }^{1}$, Boy M. Bachtiar ${ }^{1}$, Ferry P. Gultom ${ }^{1}$, Retno D. Soejoedono ${ }^{2}$ and Endang W. Bachtiar ${ }^{1, *}$ \\ ${ }^{\prime}$ Department of Oral Biology and Oral Science Research Center, Faculty of Dentistry, Universitas Indonesia, Jalan Salemba No. 4, Jakarta 10430, \\ Indonesia \\ ${ }^{2}$ Department of Immunology, Faculty of Veterinary, IPB University Dramaga Campus, Bogor 16680, Indonesia
}

\begin{abstract}
:
Purpose:

The purpose of this study was to determine the quantity of Streptococcus mutans serotype c and Candida albicans antigens from dental plaque and their relationship with the Oral Hygiene Index Score (OHI-S) and Decayed, Missing, and Filled Teeth (DMFT) in Early Childhood Caries (ECC) and Severe Early Childhood Caries (S-ECC).

\section{Materials and Methods:}

This was a cross-sectional study, including 5 ECC and 32 S-ECC subjects. ECC was classified as a DMFT score $<4$, and S-ECC was classified as a DMFT score $\geq 4$ at 71 months of age. $S$. mutans serotype c and $C$. albicans antigens from dental plaque of ECC and S-ECC patients were measured using enzyme-linked immunosorbent assays. The optical density of $S$. mutans serotype c and $C$. albicans antigens was determined at 450 $\mathrm{nm}$. Correlations between S. mutans serotype c and C. albicans antigens and OHI-S in ECC and S-ECC were analyzed.
\end{abstract}

Results:

There were no significant differences in S. mutans serotype $\mathrm{c}$ and $C$. albicans antigens between ECC and S-ECC patients or between patients with moderate and good OHI-S scores. There was a negative correlation between S. mutans serotype c and C. albicans antigens in ECC patients ( $\mathrm{r}=$ $-0,62 ; \mathrm{p}<0.05)$.

\section{Conclusion:}

The increase in C. albicans suppresses S. mutans serotype c growth in ECC but not in S-ECC. The findings of this study could be used to discover the molecular mechanisms involved in bacterial-fungal relationships and the contribution of new technologies to reduce ECC.

Keywords: Early childhood caries, Immunology, S. mutans serotype c, C. albicans, Oral Hygiene Index-Score (OHI-S), Decayed missing filled teeth (dmft).

Article History \begin{tabular}{|l|l} 
Received: July 12, 2020 & Revised: November 20, 2020
\end{tabular} Accepted: November 27, 2020

\section{INTRODUCTION}

Dental caries is a health problem with a significant incidence worldwide [1]. Specifically, there has been an increase in the incidence of caries in children, mostly on the surface of the crown and root of the teeth. There is no clear primary etiology, but Early Childhood Caries (ECC) occur in low socioeconomic groups, new immigrants, and children. This significant increase is likely caused by the lack of affordable prevention in these community groups [2].

* Address correspondence to this author at the Department of Oral Biology and Oral Science Research Center, Faculty of Dentistry, Universitas Indonesia, Jalan Salemba No. 4, Jakarta 10430, Indonesia; Tel: +6281214010491;

Fax:+6221330270; E-mail: endang04@ui.ac.id
Dental caries is an infectious disease characterized by localized tooth decay [3] and its slow progression [4]. Dental caries is a multifactorial disease, based on hosts, teeth, saliva (salivary flow), microbiota, bacteria that produce acids on the surface of teeth, and diet [3], or simply host, environment, and bacteria [5].

Caries can present as smooth surface caries, pit and fissure caries, enamel caries, dentin caries, secondary caries, ECC, and root caries [6]. According to the American Academy of Pediatric Dentistry (AAPD), ECC (formerly known as labial caries, nursing caries, and baby bottle caries) are caries that occur in children below 71 months of age [7]. ECC is characterized by the presence of one or more cavity or non- 
cavity lesions in the tooth, teeth lost due to caries, or deciduous teeth restored in pediatric patients. Severe Early Childhood Caries (S-ECC) occurs when children have smooth surface caries or if the Decaying, Missing, and Filled Teeth (DMFT) score is above or equal to the following: 4 at 3 years, above or equal to 4 at 4 years, or above or equal to 6 at 5 years of age [8]. A risk factor of ECC and S-ECC is an uncontrolled duration of bottle-feeding with sugar at night, which causes carbohydrate fermentation. The low salivary flow rate also exacerbates this during sleep $[3,9]$.

The well-known cariogenic bacteria in the formation of dental caries are Streptococcus mutans and Lactobacillus [10]. These bacteria naturally occur in small numbers in the oral cavity and cannot significantly reduce the $\mathrm{pH}$ in the oral cavity. However, this acidic environment can support the proliferation of acid-tolerant bacteria, increase demineralization, and disrupt the remineralization and demineralization of tooth enamel [11]. If demineralization is prolonged, small cavities will form in the tooth structure, which cannot be closed due to lack of remineralization, and Hydroxyapatite (HAP) crystals that are lost due to acid from bacteria [6].

Based on the chemical structure of serotype-specific rhamnose-glucose polymers, S. mutans is divided into four serotypes, namely c, e, and $\mathrm{f}$, whereas non-c/e/f serotypes in the absence of glucose groups in the bacterial polymer chain are categorized as serotype k. The prevalence of different $S$. mutans serotypes in the oral cavity varies. The highest prevalence is serotype c at $70-80 \%$, the second is serotype e approaching $20 \%$, and the remaining $5 \%$ are serotypes $\mathrm{f}$ and $\mathrm{k}$ [12]. S. mutans serotype c is common in the oral cavity of children and mothers [13].

In dental plaque, $C$. albicans can help in the progression of caries [14]. C. albicans interacts in symbiotic mutualism with S. mutans $[15,16]$ and is often detected in the oral cavity of children with ECC rather than caries-free children [17]. $C$. albicans can attach to HAP crystals and release calcium ions to destroy them. C. albicans can also produce organic acids that are more efficient at reducing $\mathrm{pH}$ than $S$. mutans [18]. Conversely, some studies have shown that $C$. albicans can raise the $\mathrm{pH}$ above the critical level, helping prevent caries [15]. Here, we evaluated the relationships between C. albicans and $S$. mutans serotype c in dental plaque of ECC patients based on their OHI-S and DMFT. In this preliminary study, enzyme-linked immunosorbent assays were used to quantify the $S$. mutans serotype c and C. albicans, which was detected using rabbit antisera [19-22].

\section{MATERIALS AND METHODS}

The sampling technique used was purposive sampling. The research subjects consisted of children under 71 months of age, and the study sample used was dental plaque taken from the study subjects.

The subjects included in the study were children who suffered from ECC and had good general health. Subjects who were not cooperative or did not experience ECC did not enter the study. The study took place at the TPA Harapan Ibu Ministry of Social Affairs Ministry, the Republic of Indonesia, in August 2019. At the screening stage, 37 participants were selected and included in the scope of the research criteria. The
Dental Research Ethics Commission of the Faculty of Dentistry of the University of Indonesia approved the study protocol (approval No.62 / Ethical Approval / FKGUI / VIII / 2019). Written informed consent was obtained from each guardian or parent of all participants.

Plaque samples on the buccal surface of the molars were taken from participants using a cotton bud and stored in an Eppendorf tube in phosphate-buffered saline. The inclusion criteria were as follows: age $<71$ months, good health, normal growth and development, absence of systemic disease or history of systemic disease, not having consumed food for two hours prior to sampling. The exclusion criteria were as follows: age $>71$ months, with systemic or congenital diseases that affect oral health, currently taking local or systemic medication.

\subsection{DMFT and OHI-S Determination}

DMFT and OHI-S scores were observed, and the totals were calculated. DMFT scores in children with deciduous teeth range from 0 to 20 , while the OHI-S ranges from 0 to 6 . The subjects were classified as

S-ECC if they had the following DMFT score: Above or equal to 4 at 3 years old, above or equal to 5 at 4 years old, or above or equal to 6 at 5 years old [8]. The OHI-S was calculated on six tooth surfaces consisting of buccal surfaces in teeth $11,16,26$, and 31 , and lingual surfaces in teeth 36 and 46.

\subsection{ELISA}

First, samples from subjects were weighed and divided based on needs, and the bottom of the wells was coated using a previously made coating buffer. Then, the ELISA work step was performed, and at the end of the stage, the $S$. mutans serotype $\mathrm{c}$ and $C$. albicans antigens were read using an ELISA reader [23, 24]. Briefly, the ELISA plates were coated with 100 $\mu \mathrm{L}$ of $1 / 100$ diluted samples and incubated overnight at $4^{\circ} \mathrm{C}$. The following day, the sample was discarded, washed three times before the well was loaded with blocking buffer and incubated for 1 hour at $37^{\circ} \mathrm{C}$. The plate was then washed three times, followed by the addition of rabbit anti-S mutans serotype $\mathrm{C}$ or $c$. albicans sera at $1 / 100$ in dilution buffer $(1 \%$ skimmed milk). Diluted sera were loaded in duplicate at 50 $\mu \mathrm{L} /$ well and incubated for 1 hour at $37^{\circ} \mathrm{C}$. The plate was then emptied by inversion and washed three times with wash buffer. Next, $50 \mu \mathrm{L}$ of $1 / 1200$ Horseradish peroxidase (HRP)conjugated anti-rabbit IgG was loaded and incubated for 1 hour at $37^{\circ} \mathrm{C}$. The HRP-conjugated anti-rabbit IgG was discarded, and the plate was washed three times with a washing buffer, followed by the addition of $50 \mu \mathrm{L}$ of TMB $\left(3,3^{\prime}, 5,5^{\prime}-\right.$ tetramethylbenzidine, Sigma-Aldrich; St. Louis, MO), and the plate was incubated for 5 minutes at room temperature. Then, $50 \mu \mathrm{L}$ of stop solution ( $1 \mathrm{~N}$ sulfuric acid) was added, followed by measuring the optical density at $450 \mathrm{~nm}$ in the ELISA reader (AccuReader, M965/M965+; Metertech, Taipei, Taiwan) $[25,26]$.

\subsection{Statistical Analysis}

The data were processed and tested for correlation between OHI-S and DMFT scores. The data were checked for normality and analyzed using Spearman and Pearson correlation. 
3
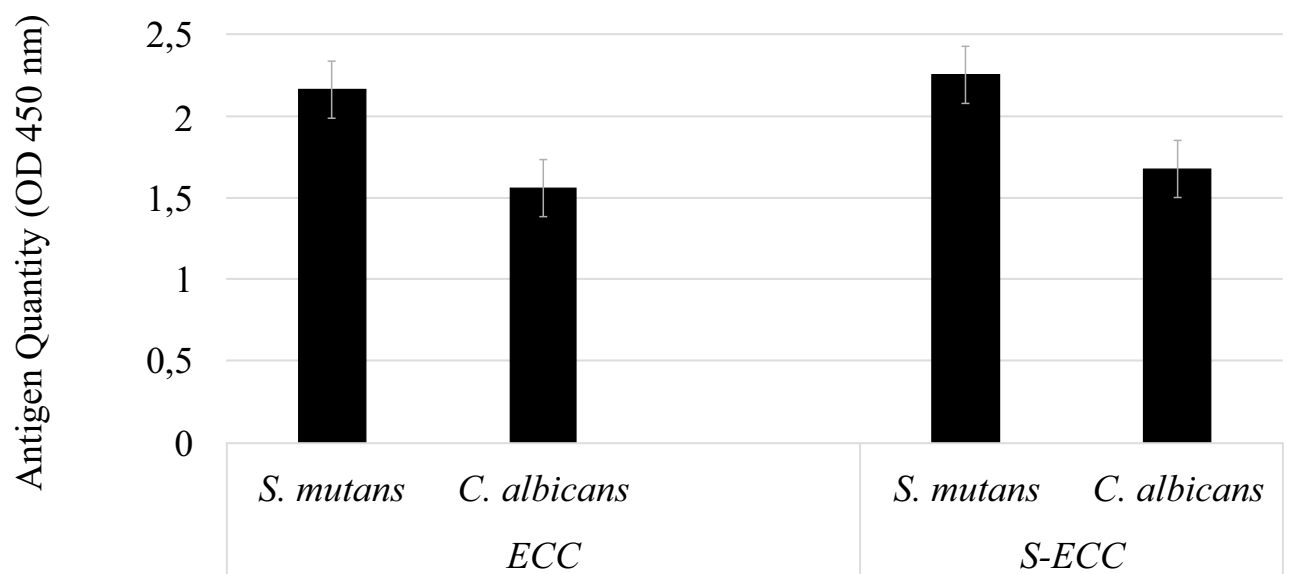

Fig. (1). Quantity of Streptococcus mutans serotype c and Candida albicans antigens in Early Childhood Caries (ECC) and Severe Early Childhood Caries (S-ECC) patients.

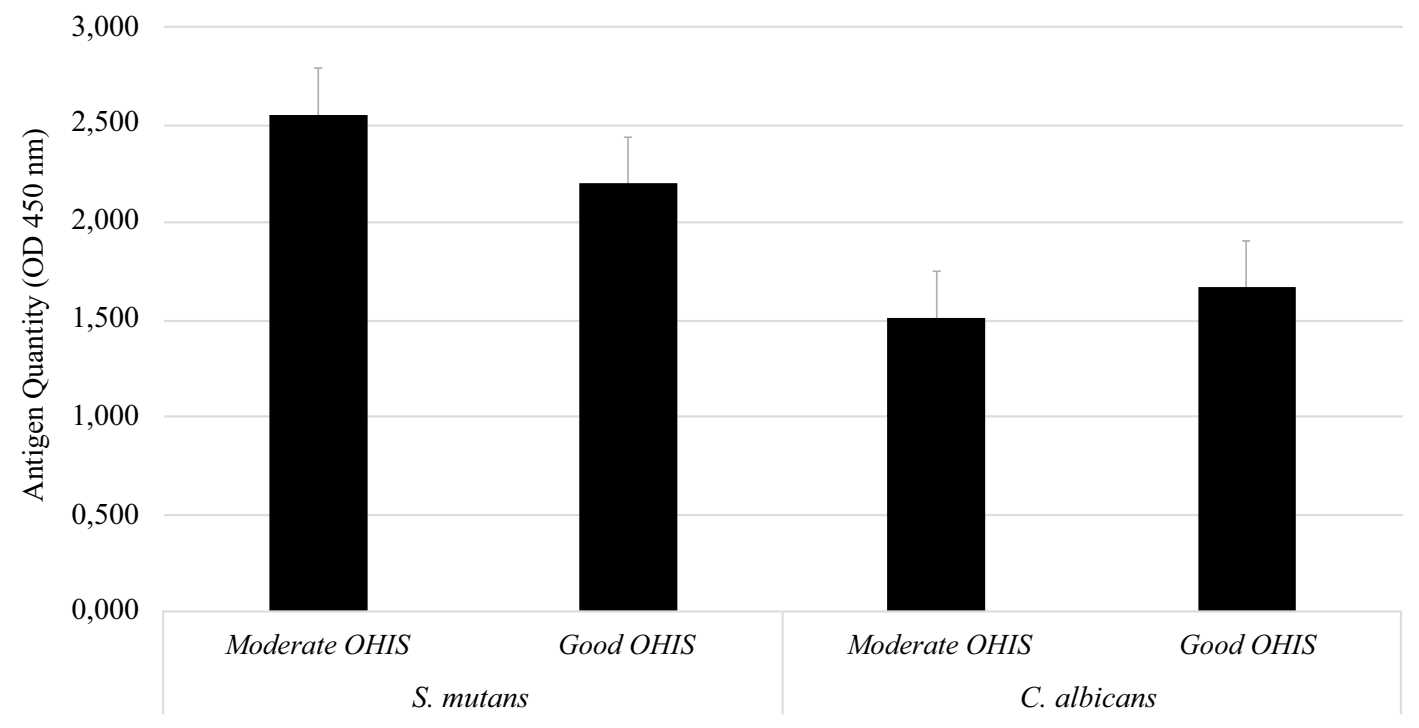

Fig. (2). Quantity of Streptococcus mutans serotype c and Candida albicans antigens based on Oral Health Index Score (OHI-S).

\section{RESULTS}

The samples were taken from the TPA Harapan Ibu Ministry of Social Affairs Republic of Indonesia from August 21-22, 2019. The number of research subjects was 39 children with ECC aged under 71 months with OHI-S and DMFT calculations.

After data recapitulation, 37 subjects with complete age, DMFT, and OHI-S information were obtained. There were 5 ECC subjects and 32 S-ECC subjects based on the definitions of ECC and S-ECC. An ELISA test was then carried out. The ELISA test results for $S$. mutans serotype c and $C$. albicans were analyzed according to the average quantity of antigens and their correlations between ECC and S-ECC patients and the OHI-S.

\subsection{Quantity of $S$. Mutans Serotype $C$ and $C$. Albicans Antigens in ECC and S-ECC Patients}

As the data were non-normally distributed, the Mann-
Whitney U test was used. As shown in Fig. (1), in both the ECC and S-ECC groups, the quantity of $S$. mutans serotype c was higher than that of $C$. albicans. There was no significant difference in the quantity of $S$. mutans serotype c in the ECC or S-ECC patient groups $(\mathrm{p}>0.05)$.

A total of 37 study subjects were grouped based on their OHI-S. Six subjects were classified as moderate and thirty-one subjects were classified as good by OHI-S. Further analysis showed no significant difference in the quantity of $S$. mutans serotype c and C. albicans between the moderate- and goodOHI-S groups ( $p>0.05)$ (Fig. 2).

\subsection{Relationship of $S$. Mutans Serotype c Antigens with $C$. Albicans Antigens from Dental Plaque in ECC and S-ECC Patients}

There was a strong negative linear correlation between $S$. mutans serotype $\mathrm{c}$ and $C$. albicans in the ECC category $(\mathrm{r}=$ $-0.620, p<0.05)$. Fig. (3) shows that the higher the number of 


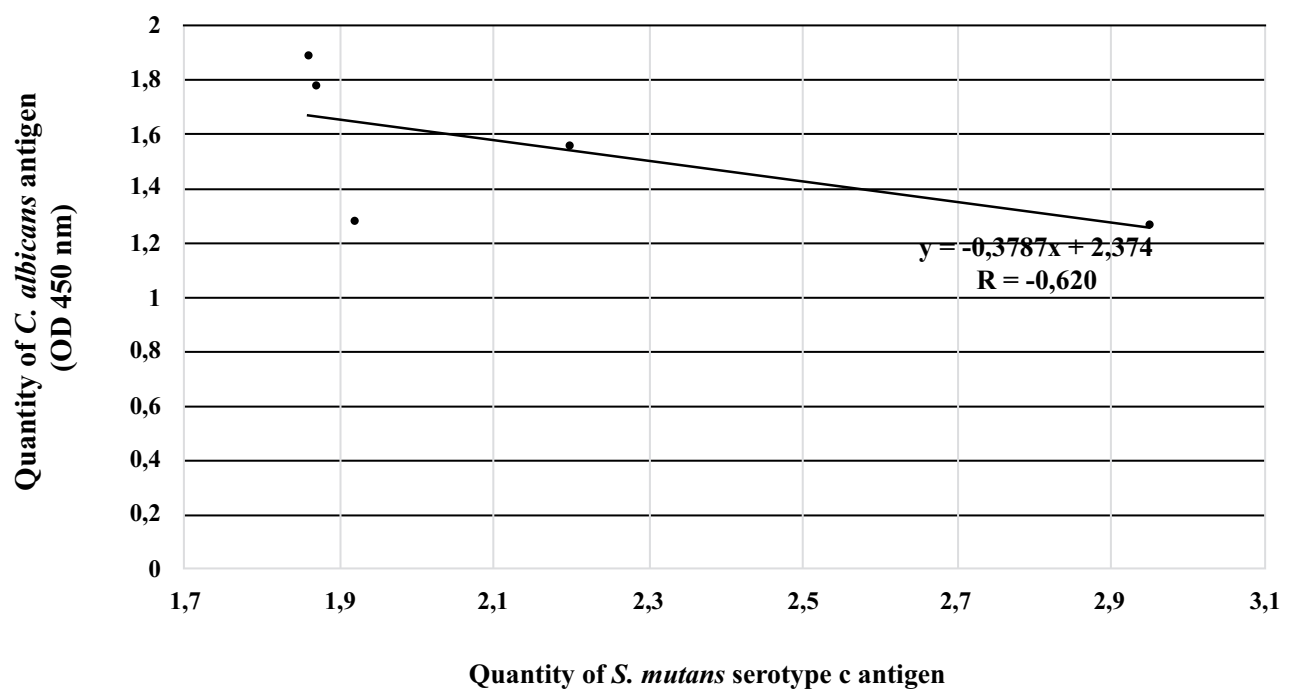

Fig. (3). Relationship of Streptococcus mutans serotype c with Candida albicans antigens from dental plaque in Early Childhood Caries (ECC) patients.

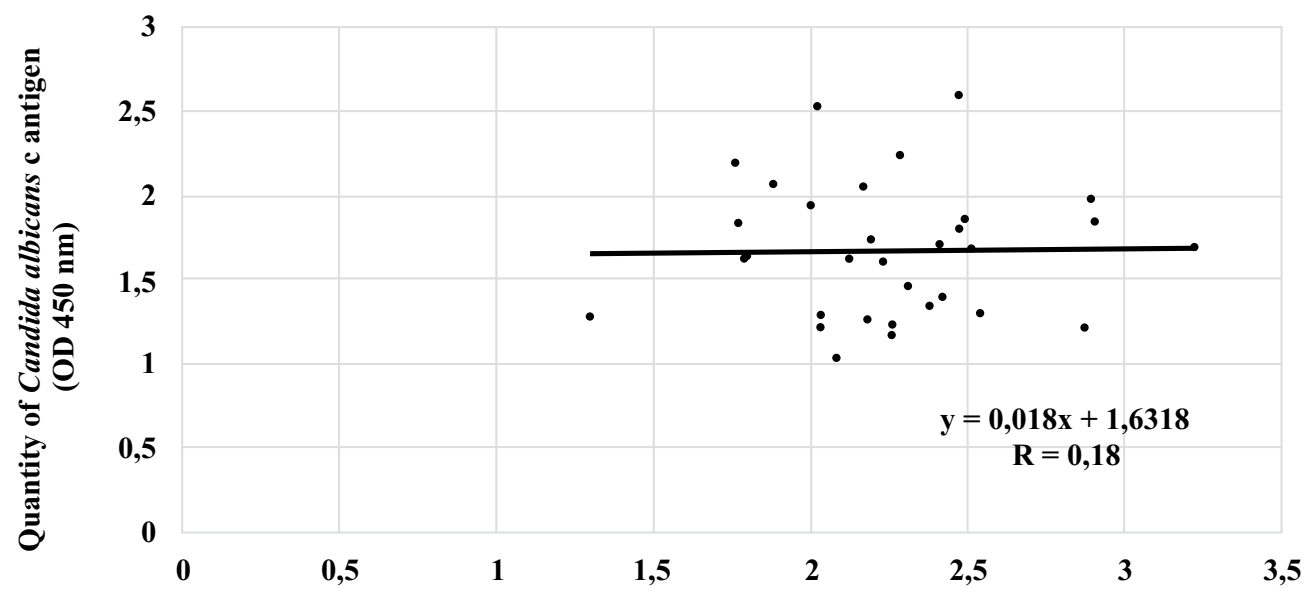

Quantity of Streptococcus mutans serotype c (OD $450 \mathrm{~nm})$

Fig. (4). Relationship of Streptococcus mutans serotype c with Candida albicans antigens from dental plaque of severe Early Childhood Caries (SECC) patients.

S. mutans serotype c, the smaller the number of C. albicans. However, this phenomenon was not observed in patients with S-ECC $(r=0.18)$ (Fig. 4).

\section{DISCUSSION}

ECC is defined as the presence of one or more damaged, lost, or repaired teeth in children aged $<71$ months or 6 years [8]. S-ECC itself is defined as ECC that has become severe with signs of smooth surface caries. This study tested 37 dental plaque samples taken from children with ECC and S-ECC and performed antigen quantity determination by ELISA.

The quantities of $S$. mutans serotype c and C. albicans antigens were calculated in ECC and S-ECC patients. S-ECC is ECC that has become severe with DMFT levels that cause partial or total damage to deciduous teeth $[26,27]$. According to a study conducted by Ledder et al. in 2018 , a significant relationship was found between the total quantity of streptococci and S-ECC in dental plaque [28]. In children with S-ECC or very extensive rampant caries, there is a high prevalence of $C$. albicans in the patient's oral environment [28]. This study revealed no significant differences in the antigen quantities of $S$. mutans or C. albicans between the ECC and S-ECC groups. These results are in line with those of Valdes et al. in 2017 and Kanasi et al., in 2010, who stated that $73 \%$ of S-ECC patients in this study had S. mutans and concluded that children with S-ECC have more dental plaque than children without caries [28]. Further, in 2017, Valdes et al. concluded that there was a linear increase in the prevalence of $S$. mutans in biofilms with the severity of caries [17].

Further analysis revealed that the antigen quantities of $S$. mutans serotype c and C. albicans were slightly higher in patients with moderate OHI-S than in those with good OHI-S. Willems et al. showed that $C$. albicans could prevent the active mineral loss, increase $\mathrm{pH}$, and prevent caries [15], resulting in 
a healthy oral cavity. This study is in line with results by Eidt et al. (2018) and Jose et al. (2014), who found that the presence of $C$. albicans could reduce the cariogenic and acirabbitenic abilities of $S$. mutans biofilms because $C$. albicans has a low demineralization ability for tooth structure $[29,30]$.

Our study found a significant negative correlation between $S$. mutans serotype c and C. albicans. This finding is in line with research from Bachtiar and Bachtiar in 2018, suggesting that there is a weak negative relationship between the quantity of $S$. mutans and C. albicans measured by qPCR from dental plaque samples in ECC patients [31].

The results of our study show that there are more $S$. mutans than $C$. albicans in ECC. We assume that there may be competition for the consumption of sugar between S. mutans serotype c and C. albicans, which may be won by S. mutans serotype c, leading to its elevated levels [31 - 33]. Jarosz et al. found that $S$. mutans was able to inhibit $C$. albicans germ tube formation in in vitro co-cultures [34]. Further research is needed to discover the molecular mechanisms involved in bacterial-fungal relationships and the contribution of new technologies to reduce ECC.

\section{CONCLUSION}

In conclusion, our findings reveal a significant negative linear relationship between $S$. mutans serotype c and $C$. albicans antigens isolated from dental plaque of ECC patients. In contrast, these results are inversely proportional to the dental plaque of patients with S-ECC; that is, there is a tendency for a weak positive relationship between $S$. mutans serotype c and $C$. albicans antigens.

\section{LIST OF ABBREVIATIONS}

$$
\begin{array}{ll}
\text { OHI-S } & =\text { Oral Hygiene Index Score } \\
\text { DMFT } & =\text { Decayed, Missing, and Filled Teeth } \\
\text { ECC } & =\text { Early Childhood Caries } \\
\text { AAPD } & =\text { American Academy of Pediatric Dentistry } \\
\text { HAP } & =\text { Hydroxyapatite } \\
\text { S-ECC } & =\text { Severe Early Childhood Caries }
\end{array}
$$

\section{ETHICS APPROVAL AND CONSENT TO PARTICIPATE}

The ethics approval was obtained from the Ethical Committee of the Faculty of Dentistry of Universitas Indonesia, Indonesia with approval no.62/Ethical approval/FKGUI/VIII/ 2019.

\section{HUMAN AND ANIMAL RIGHTS}

No Animals were used in this research. All human research procedures were followed in accordance with the ethical standards of the committee responsible for human experimentation (institutional and national), and with the Helsinki Declaration of 1975, as revised in 2013.

\section{CONSENT FOR PUBLICATION}

All patients participated voluntarily and gave their informed consent.

\section{AVAILABILITY OF DATA AND MATERIALS}

The data supporting the findings of the article is available from corresponding author [E.W.B] upon reasonable request.

\section{FUNDING}

This project was supported by PUTI Grant from Universitas Indonesia 2020 (Grant no: BA-1318/UN2.RST/PPM.00.03.01/2020).

\section{CONFLICT OF INTEREST}

The authors declare no conflict of interest, financial, or otherwise.

\section{ACKNOWLEDGEMENTS}

Declared none.

\section{REFERENCES}

[1] Ozdemir D. Dental Caries: The most common disease worldwide and preventive strategies. Int J Biol 2013; 5(4): 55-61. [http://dx.doi.org/10.5539/ijb.v5n4p55]

[2] Bagramian RA, Garcia-Godoy F, Volpe AR. The global increase in dental caries. A pending public health crisis. Am J Dent 2009; 22(1): 3-8. [PMID: 19281105]

[3] Lamont RJ, Egland PG. Dental caries molecular medical microbiology. Tang, Sussman, Liu, Poxton, Schwartzman, Ed.; Elsevier: Amsterdam 2015; pp. 945-56.

[http://dx.doi.org/10.1016/B978-0-12-397169-2.00052-4]

[4] Takahashi N, Nyvad B. Caries ecology revisited: Microbial dynamics and the caries process. Caries Res 2008; 42(6): 409-18. [http://dx.doi.org/10.1159/000159604] [PMID: 18832827]

[5] Nishikawara F, Nomura Y, Imai S, Senda A, Hanada N. Evaluation of cariogenic bacteria. Eur J Dent 2007; 1(1): 31-9. [http://dx.doi.org/10.1055/s-0039-1698309] [PMID: 19212495]

[6] Featherstone JDB. The continuum of dental caries-evidence for a dynamic disease process. J Dent Res 2004; 83 Spec No C: C39-42. [http://dx.doi.org/10.1177/154405910408301s08] [PMID: 15286120]

[7] Narvey A, Shwart L. Early childhood dental disease - what's in a name? J Can Dent Assoc 2007; 73(10): 929-30. [PMID: 18275694]

[8] Council O. Definition of Early Childhood Caries ( ECC ). 2008; 4: p. (age 3)15.

[9] Fung MHT, Wong MCM, Lo ECM, Chu CH. Early childhood caries: A literature review. J Oral Hyg Health 2013; 1(1): 1-7.

[10] Loesche WJ. Role of Streptococcus mutans in human dental decay Microbiol Rev 1986; 50(4): 353-80. [http://dx.doi.org/10.1128/MR.50.4.353-380.1986] [PMID: 3540569]

[11] Marsh PD, Head DA, Devine DA. Dental plaque as a biofilm and a microbial community - Implications for treatment. J Oral Biosci 2015; 57(4): 185-91.

[http://dx.doi.org/10.1016/j.job.2015.08.002]

[12] Nakano K, Ooshima T. Serotype classification of Streptococcus mutans and its detection outside the oral cavity. Future Microbiol 2009; 4(7): 891-902.

[http://dx.doi.org/10.2217/fmb.09.64] [PMID: 19722842]

[13] Berkowitz RJ, Jordan HV, White G. The early establishment of Streptococcus mutans in the mouths of infants Arch Oral Biol 1975; 20(3): 171-4.

[http://dx.doi.org/10.1016/0003-9969(75)90005-9] [PMID: 1054976]

[14] Meyer F, Enax J. Early childhood caries: Epidemiology, aetiology, and prevention. Int J Dent 2018; 2018: 1415873. [http://dx.doi.org/10.1155/2018/1415873] [PMID: 29951094]

[15] Willems HM, Kos K, Jabra-Rizk MA, Krom BP. Candida albicans in oral biofilms could prevent caries Pathog Dis 2016; 74(5): ftw039. [http://dx.doi.org/10.1093/femspd/ftw039] [PMID: 27129365]

[16] Koo H, Bowen WH. Candida albicans and Streptococcus mutans: A potential synergistic alliance to cause virulent tooth decay in children 
Future Microbiol 2014; 9(12): 1295-7. [http://dx.doi.org/10.2217/fmb.14.92] [PMID: 25517895]

[17] Valdez RMA, Duque C, Caiaffa KS, et al. Genotypic diversity and phenotypic traits of Streptococcus mutans isolates and their relation to severity of early childhood caries BMC Oral Health 2017; 17(1): 115. [http://dx.doi.org/10.1186/s12903-017-0406-1] [PMID: 28709424]

[18] Hemadi AS, Huang R, Zhou Y, Zou J. Salivary proteins and microbiota as biomarkers for early childhood caries risk assessment. Int J Oral Sci 2017; 9(11): e1.

[http://dx.doi.org/10.1038/ijos.2017.35] [PMID: 29125139]

[19] Lardeux F, Torrico G, Aliaga C. Calculation of the ELISA's cut-off based on the change-point analysis method for detection of Trypanosoma cruzi infection in Bolivian dogs in the absence of controls Mem Inst Oswaldo Cruz 2016; 111(8): 501-4.

[http://dx.doi.org/10.1590/0074-02760160119] [PMID: 27384081]

[20] Hornbeck P. Enzyme $\square$ linked immunosorbent assays. Curr Protocol Immunol 1992; 1(1): 2-1.

[21] Gan SD, Patel KR. Enzyme immunoassay and enzyme-linked immunosorbent assay. J Invest Dermatol 2013; 133(9): e12. [http://dx.doi.org/10.1038/jid.2013.287] [PMID: 23949770]

[22] Plested JS, Coull PA, Gidney MA. ELISA. Methods Mol Med 2003; 71: $243-61$. [PMID: 12374024]

[23] Lin AV. Indirect ELISA. Methods Mol Biol 2015; 1318: 51-9. [http://dx.doi.org/10.1007/978-1-4939-2742-5 5] [PMID: 26160563]

[24] Lardeux F, Torrico G, Aliaga C. Calculation of the ELISA's cut-off based on the change-point analysis method for detection of Trypanosoma cruzi infection in Bolivian dogs in the absence of controls Mem Inst Oswaldo Cruz 2016; 111(8): 501-4. [http://dx.doi.org/10.1590/0074-02760160119] [PMID: 27384081]

[25] Bachtiar EW, Afdhal A, Meidyawati R, Soejoedono RD, Poerwaningsih E. Effect of topical anti-Streptococcus mutans IgY gel on quantity of $S$. mutans on rats' tooth surface Acta Microbiol Immunol Hung 2016; 63(2): 159-69.

[http://dx.doi.org/10.1556/030.63.2016.2.2] [PMID: 27352970]

[26] Bachtiar EW, Soejoedono RD, Bachtiar BM, Henrietta A, Farhana N, Yuniastuti M. Effects of soybean milk, chitosan, and antiStreptococcus mutans IgY in malnourished rats' dental biofilm and the
IgY persistency in saliva. Interv Med Appl Sci 2015; 7(3): 118-23. [http://dx.doi.org/10.1556/1646.7.2015.3.6] [PMID: 26525071]

[27] Davies GN. Early childhood caries: A synopsis. Community Dent Oral Epidemiol 1998; 26(1)(Suppl.): 106-16.

[http://dx.doi.org/10.1111/j.1600-0528.1998.tb02102.x]

[PMID: 9671208]

[28] Ledder RG, Kampoo K, Teanpaisan R, McBain AJ. Oral microbiota in severe early childhood caries in thai children and their families: A pilot study. Front Microbiol 2018; 9: 2420.

[http://dx.doi.org/10.3389/fmicb.2018.02420] [PMID: 30374339]

[29] Eidt G, Andrade CG, Negrini TC, Arthur RA. Role of Candida albicans on enamel demineralization and on acidogenic potential of Streptococcus mutans in vitro biofilms J Appl Oral Sci 2019; 27: e20180593.

[http://dx.doi.org/10.1590/1678-7757-2018-0593] [PMID: 31508792]

[30] Jose T, Thomas A, Pidamale R, Mhambrey S, Shetty SB. Correlation between $C$. albicans, S. mutans, S. sanguinis and Lactobacillus in ECC, S-ECC and caries free children Int J Recent Sci Res 2014; 5: 352-6.

[31] Bachtiar EW, Bachtiar BM. Relationship between Candida albicans and Streptococcus mutans in early childhood caries, evaluated by quantitative PCR. F1000 Res 2018; 7: 1645.

[http://dx.doi.org/10.12688/f1000research.16275.2]

[PMID: 30450201]

[32] Ikono R, Vibriani A, Wibowo I, et al. Nanochitosan antimicrobial activity against Streptococcus mutans and Candida albicans dualspecies biofilms BMC Res Notes 2019; 12(1): 383. [http://dx.doi.org/10.1186/s13104-019-4422-x] [PMID: 31287001]

[33] Bachtiar EW, Dewiyani S, Surono Akbar SM, Bachtiar BM. Inhibition of Candida albicans biofilm development by unencapsulated Enterococcus faecalis cps2. J Dent Sci 2016; 11(3): 323-30. [http://dx.doi.org/10.1016/j.jds.2016.03.012] [PMID: 30894991]

[34] Jarosz LM, Deng DM, van der Mei HC, Crielaard W, Krom BP. Streptococcus mutans competence-stimulating peptide inhibits Candida albicans hypha formation Eukaryot Cell 2009; 8(11): 1658-64.

[http://dx.doi.org/10.1128/EC.00070-09] [PMID: 19717744]

(C) 2020 Rahmah et al.

This is an open access article distributed under the terms of the Creative Commons Attribution 4.0 International Public License (CC-BY 4.0), a copy of which is available at: (https://creativecommons.org/licenses/by/4.0/legalcode). This license permits unrestricted use, distribution, and reproduction in any medium, provided the original author and source are credited. 